\title{
Um ensaio sobre a macroestrutura financeira
}

Resumo: A inserção dos países subdesenvolvidos no mercado financeiro internacional condicionou o que a literatura denomina "macroestrutura financeira", que resulta da concorrência internacional de capitais promovida pelos países centrais e se manifesta na forma de diversas assimetrias, entre as quais: monetária, financeira, produtiva e tecnológica. Todas essas assimetrias se conectam, se reforçam e delimitam a ação do Estado das economias periféricas, condicionando-o a adotar políticas pró-cíclicas que beneficiam o capital especulativo. O presente artigo aponta as assimetrias que compõem a macroestrutura financeira, demonstrando suas interrelações e evidenciando a submissão de países em desenvolvimento que adotam políticas de liberalização financeira e produtiva.

Palavras-chave: Financeirização. Macroestrutura financeira. Hierarquia de moedas. Assimetria produtiva. Economia brasileira.

\begin{abstract}
The integration of developing countries in the international financial market has conditioned them to what was called in the economic literature of "financial global frame", which is a result of capital's international competition promoted by the central countries, which manifests itself in the form of various asymmetries, including: monetary; financial; productive, and; technology. All those asymmetries are mutual reinforced and delimit the action of peripheral economies, forcing state to adopt pro-cyclical policies that benefit the speculative capital. Therefore, in this paper is presented the various forms of asymmetry and their relationships, which shows the position of developing countries as dependents on the "financial global frame".
\end{abstract}

Keywords: Financerization. Financial global frame. Hierarchy of currencies. Brazilian economy.

\section{Introdução}

A partir da década de 1970, com o fim de Bretton Woods, a então potência econômica mundial, os Estados Unidos da América (EUA) tem sua posição hierárquica ameaçada por potências emergentes, em especial o Japão e a Alemanha. Tais países reestruturaram e especializaram suas atividades, revolucionando a forma industrial de produzir. A resposta americana foi centrada no seu poder monetário e financeiro e na formação de grandes grupos corporativos de atuação global (BRAGA, 1993).

Medidas adotadas pelo governo americano reduziram as regulações que coordenavam o processo de valorização do capital e, ao mesmo tempo, garantiu a manutenção hierárquica do dólar nos mercados financeiros globalizados (CARNEIRO, 1999). Como consequência, o capital passou a ser

\footnotetext{
${ }^{1}$ Mestre em Ciências Econômicas pela Universidade Estadual de Campinas. Professor do Departamento de Economia da Universidade Estadual de Montes Claros. E-mail: diogodalbuquerque@gmail.com.
}

Página 90 Caderno de Ciências Sociais Aplicadas, Vitória da Conquista/BA, vol. 15, n 26, ano 15, p. 90-110, jul/dez 2018. 
concentrado por um grupo relativamente pequeno de poderosas instituições, que não limitaram suas ações nos setores produtivos nem se restringiram localmente, mas passaram a adotar posturas agressivas no mercado financeiro global (CINTRA e CAGNIN, 2007).

As corporações americanas também ampliaram a posse de ativos financeiros, e não apenas como reserva de capital para efetuar futuros investimentos produtivos. A acumulação de ativos financeiros ganhou caráter permanente na gestão da riqueza capitalista. Isso significa que as grandes corporações passaram a gerir ativamente seus portfólios de ativos, mediante a recompra de ações, a maximização do fluxo de caixa líquido e as operações de fusões e aquisições. Elas passaram a utilizar também os instrumentos de prevenção dos riscos e a aproveitar as diferentes oportunidades de ganhos de capital oferecidas pelas expectativas de variação das taxas de juros e de câmbio no mercado financeiro global (CINTRA e CAGNIN, 2007, p. 37).

As grandes corporações dos países centrais, que agora atuam tanto no mercado financeiro como nos setores produtivos, passaram por um processo de expansão global, com concentração financeira e descentralização produtiva. Em decorrência disso, iniciou-se um processo de especialização produtiva regional, no qual as firmas dos países centrais se posicionaram em atividades de alto valor agregado e deslocaram as etapas mais simples para países da periferia. Tais firmas formam oligopólios globais que conseguem impor melhores condições tanto a jusante como a montante. Condicionam não só o mercado consumidor, com uma estratégia de diferenciação de produto e fixação de marca, mas também uma rede internacional de fornecedores (HIRATUKA e SARTI, 2011).

Com o objetivo de reduzir custos e controlar a produção, as corporações concedem e proporcionam a implantação de certas tecnologias em empresas localizadas na periferia (CHESNAIS, 1995). Essas transferências tecnológicas, somadas ao risco e ao alto custo de financiamento em Pesquisa e Desenvolvimento (P\&D), desestimulam as firmas da periferia a investir no desenvolvimento técnico-produtivo e acarretam uma restrição tecnológica que redunda em uma maior dependência dessas economias em relação às firmas dos países centrais.

Pari passu ao processo de especialização produtiva regional, a desregulação financeira internacional ampliou o fluxo de capital entre os diversos países. Assim, os executivos das grandes corporações passaram a valorizar o patrimônio dos seus acionistas por meio de operações especulativas globais (CINTRA e CAGNIN, 2007). O fluxo de capitais, apesar de ser mais frequente entre os países desenvolvidos, é outro fator que contribui para o distanciamento "evolutivo" entre as economias centrais e periféricas (ANDRADE e PRATES, 2012), como deverá será exposto.

Página 91 Caderno de Ciências Sociais Aplicadas, Vitória da Conquista/BA, vol. 15, n 26, ano 15, p. 90-110, jul/dez 2018. 
Desse modo, tanto do ponto de vista produtivo quanto financeiro, a forma de valorização desse novo paradigma é danosa à economia dos países periféricos, podendo resultar em profundas distorções internas. Não obstante, a atuação do Estado desses países passa a ser vinculada ao fluxo de capital, ou seja, o Estado passa a adotar medidas pró-cíclicas (OCAMPO, 2001), transforma-se em um refém do capital financeiro internacional e do seu moral hazard.

O que acontece nos países da periferia, apesar das particularidades de cada economia, é o que Keynes mais temia, somado ao "pesadelo" de Schumpeter. Se, por um lado, o rentismo é institucionalizado, o capital é valorizado em um “jogo de casino” (KEYNES, 1996), por outro, todo o dinamismo do capitalismo se reduz à mesa de decisões dos executivos (SCHUMPETER, 1961) que estão à frente de holdings e controlam globalmente a atividade produtiva, os fluxos de capital e a incorporação de inovações.

\section{A macroestrutura financeira}

A financeirização na qual "submergem" os "emergentes" foi gerada no processo de acumulação do capital - sob a égide dos acordos de Bretton Woods - que se processou nos países centrais, principalmente nos EUA, ao longo dos trinta anos pós Segunda Guerra (CHESNAIS, 1995).

A consecução desse novo paradigma, conforme Braga (1985), remonta à década de 1970 com o acirramento da concorrência internacional e a ameaça sobre a hegemonia econômica dos EUA, assim como a desvinculação do dólar ao padrão ouro. Nesse mesmo sentido, Carneiro (1999) elucida que a ameaça sobre a hegemonia dos países anglo-saxões fez com que estes adotassem uma postura ativa no processo de concorrência internacional ${ }^{3}$. As décadas seguintes são caracterizadas pelo recrudescimento da participação dos Estados dos países desenvolvidos, especialmente os da tríade ${ }^{4}$, na concorrência internacional capitalista (BRAGA, 1993; CHESNAIS, 1995).

\footnotetext{
2 Andrade \& Prates (2012) questionam a forma de inserção dos países periféricos no mercado financeiro internacional e a sua consequente classificação na literatura econômica como emergentes. Os autores discutem a validade desse termo ao demonstrar que na verdade não existe uma convergência, mas um distanciamento entre as economias desenvolvidas e as periféricas. Tal distanciamento é resultado da redução na liberdade da condução da própria política econômica por parte das economias periféricas.

3 Para Carneiro (1999, p. 63), "[...] a mais importante razão para o impulso à globalização e à substituição da ordem regulada de Bretton Woods foi a mudança de posição de países-chave no sistema internacional, especialmente os anglosaxões, no final dos anos 70."

${ }^{4}$ Termo utilizado por Chesnais (1995) para se referir aos Estados Unidos da América, Japão e Alemanha, países que estão à frente da disputa internacional pelos mercados consumidores e produtores.
}

Página 92 Caderno de Ciências Sociais Aplicadas, Vitória da Conquista/BA, vol. 15, n 26, ano 15, p. 90-110, jul/dez 2018. 
A principal arma utilizada nessa disputa foi o capital financeiro, que passou a ser beneficiado com políticas de desregulamentação e privatização iniciadas por Thatcher e Reagan (CHESNAIS, 1995; ANDRADE e PRATES, 2012). Apesar disso, as medidas adotadas por Volcker, enquanto chefiava o Federal Reserve, determinaram a continuação da posição hierárquica do dólar como moeda chave e símbolo absoluto da liquidez (CONTI, BIANCARELLI e ROSSI, 2013). As mudanças institucionais que marcaram essa fase de transição e definiram o paradigma atual de valorização de capital são resumidas por Coutinho \& Belluzzo (1996) no seguinte parágrafo:

As decisões políticas tomadas pelo governo americano, ante a decomposição do sistema de Bretton Woods, foram ampliando o espaço supranacional de circulação do capital monetário. A política americana de reafirmar a supremacia do dólar acabou estimulando a expansão dos mercados financeiros internacionais, primeiro através do crédito bancário - euromercados e off shores - e mais recentemente através do crescimento da finança direta. Paradoxalmente, as tentativas de assegurar a centralidade do dólar nas transações internacionais ensejaram o surgimento de um instável e problemático sistema plurimonetário com paridades cambiais flutuantes. Neste cenário, as economias periféricas são atingidas por fatores independentes às condições de reprodução da sua estrutura financeira e produtiva que passa a sofrer constantes e profundos processos adaptativos em decorrência dos choques internacionais (COUTINHO e BELLUZZO, 1996, p. 152).

Não obstante, Coutinho e Belluzzo (1996) defendem que tais transformações marcam um rompimento com o anterior paradigma da macroeconomia aberta, caracterizado por um sistema de proteção industrial e por incentivos à atração de multinacionais. O novo paradigma é marcado pela completa desregulamentação e foi possibilitado graças à revolução tecnológica da informação e nas comunicações (PÉREZ, 2010).

Entre os pós-keynesianos a conceituação do novo paradigma é variada, alguns, entre os quais se inclui Braga ${ }^{5}$ (1993), denominam-no de financeirização. Diferentemente, Chesnais (1995) propôs o termo "mundialização" ou "globalização financeira". Não obstante essa diversidade, alguns autores alternam essas conceituações com o termo - mais emblemático e também utilizado no paradigma anterior - globalização. Entre eles, estão Coutinho e Belluzzo (1996), Carneiro (1999) e Ocampo (2001).

\footnotetext{
${ }^{5}$ Braga (1993, p. 26) define a financeirização como “[...] expressão geral das formas contemporâneas de definir, gerir e realizar riqueza no capitalismo".

${ }^{6}$ Chesnais $(1995$, p. 1) define o novo paradigma como " [...] um novo regime mundial de acumulação, cujo funcionamento dependeria das prioridades do capital privado altamente concentrado - do capital aplicado na produção de bens e serviços, mas também, de forma crescente, do capital financeiro centralizado, mantendo-se sob a forma de dinheiro e obtendo rendimento como tal".
}

Página 93 Caderno de Ciências Sociais Aplicadas, Vitória da Conquista/BA, vol. 15, n 26, ano 15, p. 90-110, jul/dez 2018. 
A despeito da abrangência conceitual, os pós-keynesianos concordam que o novo paradigma se caracteriza pelo enorme fluxo internacional de capital, concentrado e coordenado por instituições financeiras cujo único objetivo é a valorização da riqueza. Para Conti et al. (2013) e Rossi (2013), tais instituições atuam globalmente por meio de operações de curto prazo, coordenando enormes massas de riqueza em um ambiente desregulado e propício à rápidas e avassaladoras reversões.

A forma de inserção das economias periféricas, em especial dos países da América Latina, no mercado financeiro internacional, restringiu a política econômica desses países às condições de reprodução e à instabilidade do capital financeiro (OCAMPO, 2001). Em vez de centrar esforços para a superação ao subdesenvolvimento, os Estados desses países passaram a ficar sobrecarregados com o alto custo da estabilidade de uma economia aberta e vulnerável ao capital financeiro especulativo (BRUNO, 2012).

Com efeito, a política monetária se manifesta tal qual uma ferramenta cuja finalidade seria controlar os desequilíbrios cambiais gerados pelos constantes movimentos especulativos do capital financeiro internacional (ANDRADE e PRATES, 2012; CONTI, BIANCARELLI e ROSSI, 2013). O manejo das reservas internacionais e o estímulo às exportações vão no mesmo sentido (ANDRADE e PRATES, 2012).

Quanto mais aberto e integrado for o mercado, maiores são as consequências para a economia periférica. Nessas economias, a instabilidade é a regra. Seus ciclos são determinados pelo ciclo de valorização do capital financeiro internacional. Suas principais variáveis como o investimento, o balanço de pagamentos e até o gasto do governo e o consumo das famílias passam a acompanhar tal oscilação (COUTINHO e BELLUZZO, 1998).

Nessa perspectiva, Ocampo (2001) relata que as economias periféricas não são autossuficientes no processo de valorização de capital e muito menos na consecução do seu desenvolvimento. Essas economias seriam "business cycle/policy takers", pois internalizariam as consequências dos distúrbios gerados no exterior e também arcariam com os custos de políticas prudenciais que teriam a função de evitar que tais distúrbios se traduzam em uma potencial crise sistêmica.

As economias periféricas são suscetíveis a tais imposições em decorrência de assimetrias que se reforçam e que são responsáveis pelo continuo distanciamento econômico entre as economias “desenvolvidas" e "subdesenvolvidas" (ANDRADE e PRATES, 2012; OCAMPO, 2001). Nesse sentido foi construído o Fluxograma 1 que apresenta as principais assimetrias em que se processa a concorrência internacional capitalista.

Página 94 Caderno de Ciências Sociais Aplicadas, Vitória da Conquista/BA, vol. 15, n 26, ano 15, p. 90-110, jul/dez 2018. 


\section{Cadernos de Ciências SOCIAIS APLICADAS}

Fluxograma 1 - A macroestrutura financeira da concorrência capitalista internacional

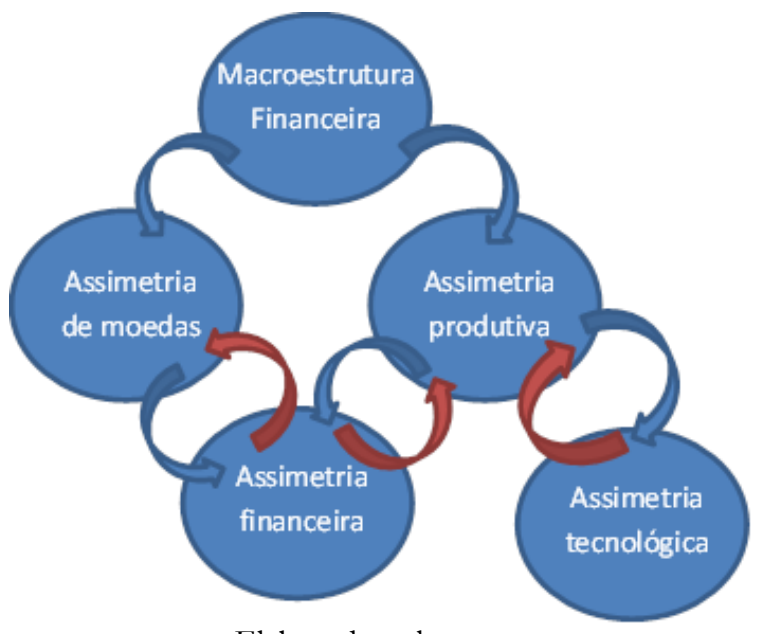

Elaborado pelo autor.

No Fluxograma 1, observa-se que a concorrência capitalista internacional ocorre em uma "macroestrutura financeira" conferida sobre diversas assimetrias. A assimetria de moedas, estudada por autores como Andrade \& Prates (2012) e Conti et al. (2013), apresenta forte influência sobre o mercado financeiro global, que, por sua vez, afeta a assimetria produtiva. Esta última é associada ao poder financeiro e tecnológico das firmas, como trata Braga (1993), mas também é influenciada indiretamente pela assimetria de moedas.

As assimetrias de moeda e produtiva seriam em conjunto responsáveis pela assimetria financeira que, por sua vez, reforçaria as assimetrias anteriores. Já a assimetria tecnológica entre os diversos países seria resultado da assimetria produtiva, ao tempo que a reforçaria, como colocado por Ocampo (2001). Mas, perceba que a assimetria tecnológica também sofre impacto indireto da assimetria financeira e da monetária, isso deverá ficar mais claro a posteriori.

O primeiro círculo do Fluxograma 1 - "macroestrutura financeira" - foi o termo usado por Braga (1993) para definir o papel preponderante das finanças no processo de concorrência internacional capitalista em que grandes corporações e instituições públicas estariam "vinculadas à questão financeiro-monetária" (BRAGA, 1993, p. 39), proporcionando a formação de grandes grupos de capitalistas que competiriam não apenas em âmbito nacional, mas internacional e intersetorialmente.

A "macroestrutura financeira" caracteriza-se pela ação do Estado das economias centrais na consecução de uma concorrência intercapitalista global composta por diversas assimetrias que se realimentam, tais quais as descritas no Fluxograma 1, evidenciadas a seguir.

Página 95 Caderno de Ciências Sociais Aplicadas, Vitória da Conquista/BA, vol. 15, n 26, ano 15, p. 90-110, jul/dez 2018. 


\subsection{Assimetria de moeda}

Para tratar da primeira assimetria da concorrência internacional capitalista - a assimetria, ou hierarquia, de moedas - é importante salientar que a economia capitalista está inserida em uma ordem monetária, em que o dinheiro se comporta como um ativo cuja propriedade fundamental, a liquidez ${ }^{7}$, "acalenta" aqueles que fogem da instabilidade, da incerteza da atividade financeira e da valorização fictícia (MINSKY, 2008; ANDRADE e PRATES, 2012). O dinheiro tem a função de validar toda e qualquer atividade capitalista, portanto, qualquer fator que afete o fluxo do dinheiro altera a confiança dos capitalistas e potencializa uma reversão.

That is the financing schema of a capitalist economy where the money is transversal and takes everything into its oscillations since all economic transactions rely on monetary relations. Monetary and financial problems are then structurally related to all other sectors through the changes of credit strategies of banks, changes of market strategies of financial intermediaries or through the lack of confidence on repayment ability of borrowers (ÜLGEN, 2014, p. 267).

A característica de liquidez inerente ao dinheiro centra-se no seu potencial de exercer as seguintes funções: unidade de conta, meio de troca e reserva de valor. Cada país, individualmente, pode ter uma moeda que apresente localmente tais atributos. Contudo, no âmbito internacional apenas algumas moedas são capazes de conter todas as funções citadas.

Mesmo as moedas internacionalmente aceitas não são homogêneas e apresentam diferentes prêmios de liquidez (OCAMPO, 2001). Para Conti et al. (2013), o dólar se apresenta como divisa chave e liquidez por excelência no topo da hierarquia internacional das moedas. O Euro teria um prêmio de liquidez um pouco inferior ao dólar, posicionando-se logo abaixo deste, e sendo acompanhado por outras moedas que não deixam de cumprir as funções clássicas da moeda no cenário internacional, como a Libra e o Yen. Esses três níveis da hierarquia compõem o que Conti et al. (2013) denominaram moedas centrais (“Central Currencies”). Por fim, apresentam-se as moedas que não cumprem as funções clássicas da moeda no âmbito internacional, tais quais as das economias periféricas.

As moedas das economias periféricas, por apresentarem reduzida liquidez, possuem altos prêmios de riscos e por isso são transacionadas no mercado internacional, não por suas qualidades como moeda, mas como ativos (ANDRADE e PRATES, 2012).

\footnotetext{
7 Andrade \& Prates (2012) determinam o termo liquidez como a capacidade de comprar e vender determinado ativo, de modo que a firma consiga saldar seus débitos ao compasso dos seus relativos vencimentos.
}

Página 96 Caderno de Ciências Sociais Aplicadas, Vitória da Conquista/BA, vol. 15, n 26, ano 15, p. 90-110, jul/dez 2018. 


\title{
2.2 Assimetria financeira
}

Como essa assimetria resulta das hierarquias monetárias e produtivas e, ao mesmo tempo, contribui para a manutenção e a ampliação de ambas, esse quesito deve ser estudado em duas partes.

\subsubsection{Relação entre as assimetrias monetária e financeira:}

A assimetria de moeda condiciona uma assimetria financeira, que se manifesta tanto nas diferenças quantitativas e qualitativas dos fluxos de capitais como na forma de inserção dos países periféricos no mercado financeiro. Nas palavras de Andrade \& Prates (2012):

\begin{abstract}
À assimetria do sistema monetário internacional sobrepõe-se a assimetria do sistema financeiro internacional, a qual possui duas dimensões. A primeira refere-se aos determinantes dos fluxos de capitais direcionados aos países emergentes. Esses fluxos dependem, em última instância, de uma dinâmica exógena a esses países, que estão permanentemente vulneráveis à sua reversão, decorrente tanto de mudanças na fase do ciclo econômico e/ou na política econômica, em particular a monetária, dos países centrais, como do aumento da preferência pela liquidez dos investidores de portfólio globais. A segunda dimensão da assimetria financeira diz respeito à inserção marginal desses países periféricos emergentes nos fluxos de capitais globais (ANDRADE e PRATES, 2012, p. 251 e 252).
\end{abstract}

Andrade \& Prates (2012) e Conti et al. (2013) interpretam que a alocação internacional da riqueza, típica do regime de acumulação financeira, ocorre mediante ativos cambiais, que - na mesma perspectiva de Keynes (1996) - apresentam diferentes quasi-rendas (q), prêmio de liquidez (1), custo de carregamento (c) e expectativas de valorização (a). Na etapa de expansão a "exuberância irracional" é proeminente e o prêmio de liquidez reduzido. Os investidores internacionais aumentam a alocação em ativos mais "exóticos" vinculados a moedas periféricas. Esse fluxo permanece enquanto o prêmio de liquidez (l) continuar reduzido e a expectativa de valorização (a) persistir (CONTI, BIANCARELLI e ROSSI, 2013).

Apesar do fluxo financeiro nos países periféricos representar apenas uma pequena parte dos fluxos registrados nos países desenvolvidos (ANDRADE e PRATES, 2012), eles são praticamente unidirecionais, baseados em convenções e capazes de distorcer as taxas de câmbio e, consequentemente, afetar as condições de estabilidade macroeconômica dos países mais fragilizados e abertos (CONTI, BIANCARELLI e ROSSI, 2013). Os países que adotam um regime cambial flexível

Página 97 Caderno de Ciências Sociais Aplicadas, Vitória da Conquista/BA, vol. 15, n 26, ano 15, p. 90-110, jul/dez 2018. 
são os que mais sofrem com a volatilidade dos fluxos internacional de riqueza e, principalmente, com operações de carry trade ${ }^{8}$ (ROSSI, 2013).

Um choque no processo de valorização de capital nos países centrais, ou na adoção de uma política restritiva por seus Estados, resulta em aumento da preferência pela liquidez dos investidores institucionais internacionais e inicia uma venda em "massa" de ativos nas economias periféricas, podendo acarretar uma profunda deflação nos preços de tais produtos.

O movimento cíclico é assimétrico, a reversão é rápida e avassaladora. O mecanismo de transmissão advém principalmente do câmbio, que tende a ser apreciado (ROSSI, 2013). A rápida apreciação do câmbio pode acarretar em outros movimentos especulativos que recrudesce esse movimento, com efeitos sobre a fuga de capitais e cerceamento do consumo e investimento dos nacionais (COUTINHO e BELLUZZO, 1998). Nesse sentido, os Estados das economias periféricas são condicionados a adotar políticas pró-cíclicas, de modo a garantir a manutenção dos fluxos monetários.

A adoção de políticas pró-cíclicas por parte dos Estados periféricos, tais quais as descritas em Ocampo (2001), visa controlar os distúrbios da inflação - inflamada durante o processo de expansão e agravada após a desvalorização cambial - e evitar uma crise cambial. As políticas adotadas centram-se na ampliação da taxa de juros e na gestão de reservas cambiais. Tais medidas provocam uma redução do consumo das famílias, em função tanto da reavaliação do mercado sobre seus estoques de riqueza como pelo efeito cambial, e uma redução do investimento por parte dos empresários, que têm seus lucros corroídos tanto pela redução do consumo como pelo aumento da taxa de juros (COUTINHO e BELLUZZO, 1998).

Em conclusão, é o fato de haver hierarquia de moeda que os detentores da riqueza financeira mundial exigem maiores prêmios de risco para atuar no mercado financeiro das economias periféricas. Na recessão ocorre uma fuga para as "Central Currencies", em especial para o dólar, o que implica adoção de medidas pró-cíclicas por parte dos governos das economias periféricas que, por sua vez, afetam as condições internas de valorização do capital.

\footnotetext{
${ }^{8}$ Frankel (2008 apud Rossi, 2013, p.4) define as operações de carry trade como "Indeed, a useful, still broader definition of the carry trade would cover any investment strategy that involved shifting out of low-interest-rate assets and into anything else -- emerging market debt, equities, real estate, commodities, and the like" (FRANKEL, 2008, p. 38 apud Rossi, 2013, p.4). Gagnon \& Chaboud (2007 apud Rossi, 2013, p. 4) conceituam dois tipos de operações de carry trade: 1) "canonical carry trade", aplicações em ativos de uma moeda financiadas por empréstimos em outra moeda, e; 2) "derivatives carry trade", aplicações em que os especuladores atuam comprados na moeda com juros altos e vendidos em moeda de juros baixos.
}

Página 98 Caderno de Ciências Sociais Aplicadas, Vitória da Conquista/BA, vol. 15, n 26, ano 15, p. 90-110, jul/dez 2018. 


\section{- Cadernos de Ciénclas SOCIAIS APLICADAS}

A percepção de risco dos mercados financeiros dos países periféricos, que determina o fluxo de capitais para esses países, é formada de acordo com os ciclos das economias centrais. No gráfico 1 essa relação hierárquica fica mais clara. Nesse caso, a variação da bolsa americana Nasdac claramente subjuga a apreciação dos títulos brasileiros. Vemos que após a crise cambial de 1999 há uma relação inversa entre a valorização de ativos no mercado financeiro americano e o prêmio de risco cambial somado ao risco país no Brasil ${ }^{9}$. Quanto maior o risco país, maior é a rentabilidade exigida por qualquer capital alocada no país, o que, ceteris paribus, condiciona a necessidade de um aumento da rentabilidade de títulos públicos, ou seja, da taxa de juros.

Gráfico 1 - Relação entre a valorização dos ativos na bolsa americana Nasdac e o spreed soberano para aplicações em títulos de dívida dos países "emergentes" somado ao Risco

Brasil.

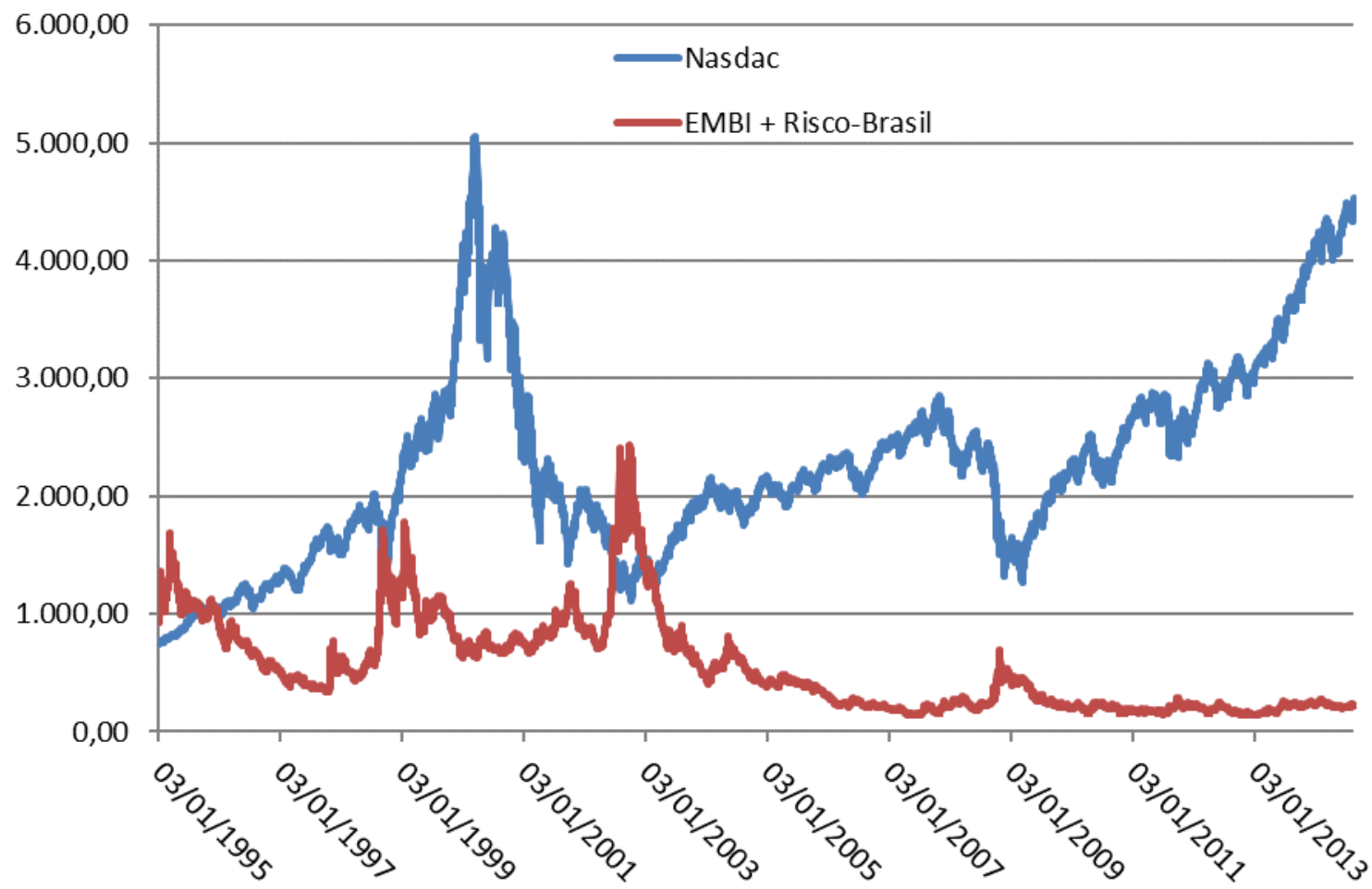

Fonte: IpeaData. Elaborado pelo autor.

\footnotetext{
9 O EMBI+ é um índice construído pelo JP Morgan, que retrata o retorno dos títulos de dívida emitidos por países emergentes (IPEADATA).
}

Página 99 Caderno de Ciências Sociais Aplicadas, Vitória da Conquista/BA, vol. 15, n 26, ano 15, p. 90-110, jul/dez 2018. 


\subsubsection{Relação entre as assimetrias produtiva e financeira:}

A desregulamentação financeira nos países periféricos condiciona a adoção de práticas rentistas nesses mercados e acarreta dificuldades no setor produtivo dessas economias. Expansões nos mercados tradicionais transbordam para os mercados periféricos, infligindo um processo de inflação de ativos, que desestimula a aplicação de recursos na formação de novos ativos produtivos (BRUNO, 2012). Por outro lado, recessões no centro são imediatamente assimiladas na periferia por meio de choques cambiais seguidos por políticas pró-cíclicas, como o aumento da taxa de juros (COUTINHO e BELLUZZO, 1998).

Bruno (2012) chama atenção para o fato de que a entrada líquida de recursos financeiros no Brasil ao longo da década de 1990, em decorrência da abertura financeira nacional, não se traduziu em um aumento significativo do estoque de capital, mas significou constantes alterações nos direitos de propriedade do capital existente. Assim, ele critica a versão dos economistas defensores do modelo de liberalização financeira, que argumentam a importância desse processo na formação interna de poupança.

Nesse sentido, a poupança pode ser dividida em "produtiva" e "improdutiva" (AGLIETTA, 2008 apud BRUNO, 2012). Esta última é relativa a fluxos de recursos não consumidos e não investidos, que são apenas utilizados para a transferência de direitos de propriedade dos ativos existentes. Enquanto a poupança produtiva seria aquela alocada na consecução de novos ativos produtivos, que elevaria a base "real" e não "psicológica" da riqueza da sociedade.

O fato é que a financeirização desvia recursos de investimentos produtivos e os destina às atividades especulativas. Assim, a financeirização reduz a formação de poupança que seria derivada do aumento do capital fixo (BRUNO, 2012).

Consequentemente, para uma dada margem de lucro sobre o estoque de capital fixo, a financeirização reduz a parte da poupança empresarial (lucro retido) que poderia ser alocada em ativos produtivos em prol das alocações em ativos financeiros. Este processo bloqueia, portanto, a formação endógena de poupança, já que esta depende do desenvolvimento da acumulação de capital fixo produtivo e não das alocações financeiras (BRUNO, 2012, p. 10).

Além de não aumentar significativamente os recursos disponíveis para o investimento em setores produtivos, a liberalização financeira no Brasil também elevou a instabilidade desse tipo de alocação de recursos. Tobin (1969) relaciona o setor produtivo ao financeiro e demonstra como os

Página 100 Caderno de Ciências Sociais Aplicadas, Vitória da Conquista/BA, vol. 15, n 26, ano 15, p. 90-110, jul/dez 2018. 
investimentos são avaliados na órbita financeira (TOBIN, 1969, \& BOLTON, CHEN e WANG, 2016). Para Tobin (1969), os preços das ações no mercado financeiro seriam uma boa aproximação da avaliação do mercado para os investimentos a serem realizados pelas empresas.

Não obstante, com a abertura financeira do Brasil, investidores institucionais passaram a alocar seus recursos de modo especulativo na bolsa de valores, o que provocou uma distorção nos preços dos ativos negociados no pregão e reduziu a capacidade dos boards das empresas em determinar os melhores investimentos e em quais momentos realizá-los.

O board toma decisões que maximizam não o lucro da empresa em longo prazo, mas seus próprios retornos. Como os rendimentos dos executivos são atrelados ao desempenho financeiro da empresa no curto prazo, monitorados e constantemente avaliados no mercado, a tomada de decisão passa a ser atrelada ao rendimento financeiro de agentes especulativos, ao passo que negligencia investimentos necessários para a sobrevivência e o crescimento da empresa em longo prazo (CINTRA e CAGNIN, 2007).

A estrutura difusa de propriedade das ações corporativas e a natureza dos mecanismos
que disciplinam a administração das empresas condicionam a dinâmica do mercado de
controle corporativo (market for corporate control). Os executivos das empresas devem
seguir a disciplina imposta pelos mercados: se a corporação for mal gerenciada (under-
performing management) e/ou se os dividendos forem negligenciados, os investidores
reagirão, vendendo ações. Consequentemente, seus preços se deprimirão e a empresa
ficará exposta a processos hostis de takeovers [...]. Essa dinâmica forma um sistema
empresarial extremamente competitivo, em que prevalece a tirania dos balanços
trimestrais, uma vez que as performances das corporações são permanentemente
monitoradas pelos mercados (CINTRA e CAGNIN, 2007, p. 38).

Poderosas instituições financeiras são responsáveis por grande parte do volume de recursos transacionados diariamente no mercado financeiro. Essas transações não são tomadas em consequências de boas ou más decisões da alta gerência, mas objetivando maximizar os rendimentos financeiros controlados por enormes instituições financeiras de ação global.

Antes um bom sinalizador de investimentos, atualmente a bolsa de valores se transforma em um “jogo de cassino" global, em que apenas grandes players “sentam-se à mesa”. Qualquer quebra nas expectativas desses players afeta os mercados emergentes, entre eles, o brasileiro.

No gráfico 1, é possível vislumbrar a dependência do mercado financeiro brasileiro em relação às expectativas do mercado financeiro global. $\mathrm{Na}$ figura 1 , é apresentada uma relação entre o rendimento (diferença do logaritmo natural) médio diário do Ibovespa (Ybm) com o Nasdaq Composit

Página 101 Caderno de Ciências Sociais Aplicadas, Vitória da Conquista/BA, vol. 15, n 26, ano 15, p. 90-110, jul/dez 2018. 


\section{- Cadernos de Ciénclas SOCIAIS APLICADAS}

(Ynym). A figura mostra também a correlação entre essas variáveis, além da correlação dessas com o rendimento médio diário do FTSE London. A correlação entre o rendimento médio da bolsa brasileira e aqueles observados nos índices americano e inglês é de aproximadamente 0.6. Porém, a correlação encontrada entre esses dois últimos índices é bem superior, 0,7669.

Figura 1 - Rendimento médio diário do Ibovespa e do NASDAQ e sua correlação

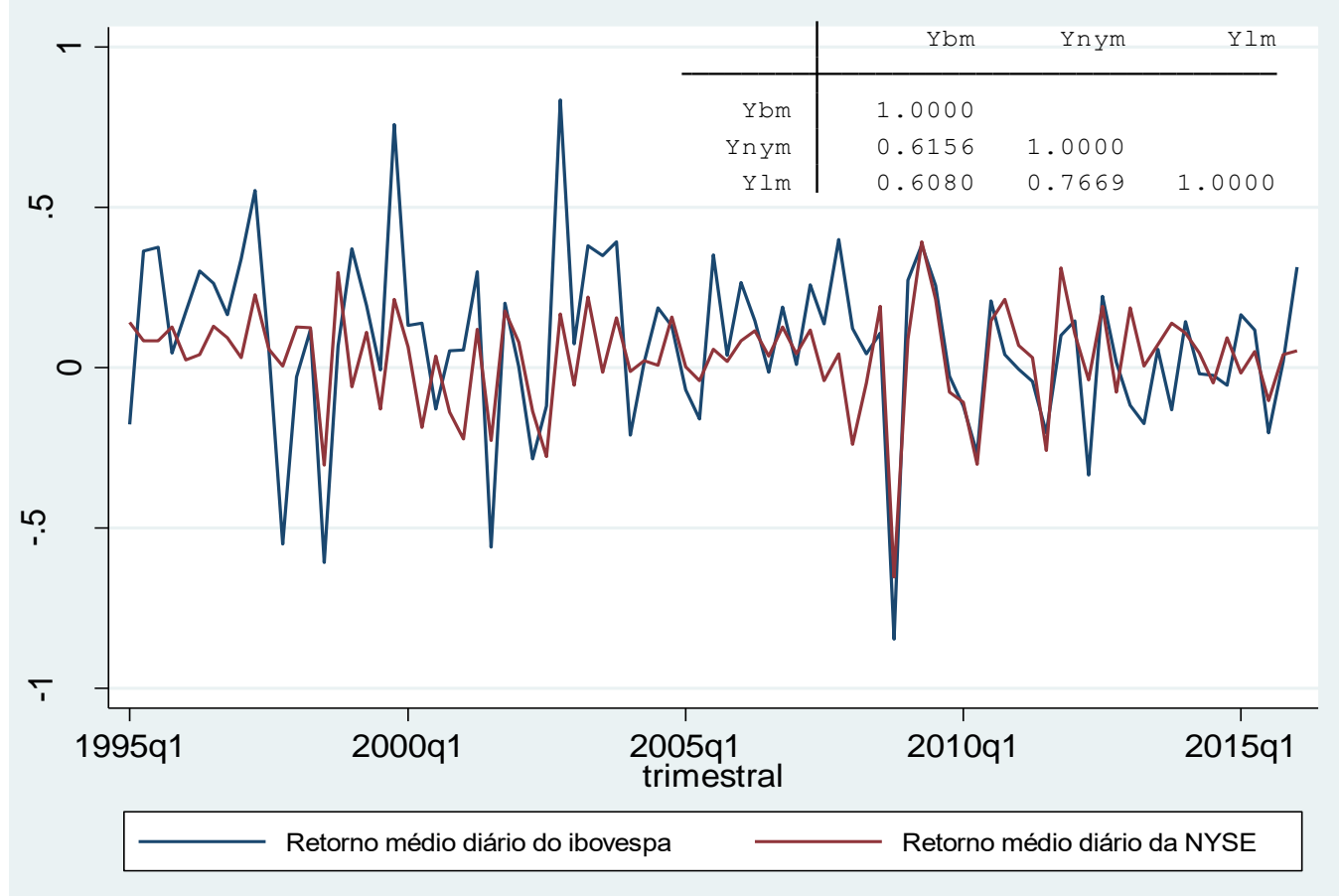

Fonte: Banco Central do Brasil, Nasdaq e London Stock Exchange.

Devido às constantes e fortes flutuações que as economias periféricas inseridas no mercado financeiro internacional enfrentam, a assimetria financeira reforça a assimetria produtiva por impedir um processo estável, continuo e sustentável de valorização de capital.

\subsection{Assimetria produtiva}

Além da desregulamentação da circulação internacional do capital financeiro e da relação de hierarquia entre as moedas, a "macroestrutura financeira" incorpora processos de concentração produtiva com vistas ao acirramento dos capitais globais, que ocorre mediante o aumento do controle do progresso técnico e da propriedade sobre o estoque de capital.

Página 102 Caderno de Ciências Sociais Aplicadas, Vitória da Conquista/BA, vol. 15, n 26, ano 15, p. 90-110, jul/dez 2018. 
Para Chesnais (1995), a concentração do capital condiciona o setor produtivo e se manifesta como uma estratégia de concorrência global. Grandes grupos industriais compõem oligopólios que perpassam as fronteiras regionais e concorrem aos mercados globais. Ao competir internacionalmente, os oligopólios possuem uma relação de dependência mútua, que se manifesta na forma de acordos de cooperação que elevam às barreiras à entrada de possíveis concorrentes (PORTER, 1986).

O objetivo desses grupos industriais é aumentar o poder em todo o globo mediante fusões e aquisições e pela adoção de processos que reduzem os custos de produção por meio de mudanças nas relações de classe. Esse foi o caso da utilização de modelos de produção tipo toyotista e just-in-time subcontratando empresas em países da periferia, especializadas nas etapas de produção mais simples e com relações trabalhistas flexíveis e favoráveis ao capital (CHESNAIS, 1995).

Finalmente, e mais importante, a fase de mundialização do capital não pode ser dissociada do modo pelo qual os grupos industriais procuraram afrouxar as restrições em três níveis - o do crescimento dito "externo" (via aquisições e fusões), que permite adquirir rapidamente fatias de mercado, o da ruptura das relações fordistas com os assalariados e aquele da internacionalização crescente (CHESNAIS, 1995, p. 8).

Chesnais (1995) conclui que a organização do sistema produtivo-financeiro global ocorre por intermédio de holdings que operam internacionalmente e constituem grandes grupos financeiros que dominam a atividade produtiva internacional. Essas holdings operam crescentemente por meio do mercado de câmbio e condicionam a criação de redes produtivas mediante "acordos entre desiguais". Para as firmas regionais de países periféricos e "Para muitas firmas pequenas, o único meio possível de sobrevivência consiste na 'adesão' a uma 'firma-rede' do tipo Benetton, ou seja, em se transformar em subcontratadas" (CHESNAIS, 1995, p. 24). No mesmo sentido Sarti \& Hiratuka (2010) apontam:

Dessa forma, o processo de produção passou a ocorrer sob forma de uma rede internacional integrando diferentes países e diferentes empresas, realizando etapas da cadeia de valor sob a coordenação das grandes corporações, que gerenciam suas próprias filiais e as demais empresas da rede com o objetivo de obter o máximo de retorno para o conjunto das suas atividades (SARTI e HIRATUKA, 2010, p. 9).

Assim, por um lado, a mundialização proporcionou um aumento na concentração dos direitos de capital com o auxílio de processos de fusões e aquisição de empresas (CHESNAIS, 1995). Por outro, há uma descentralização que desponta a divisão internacional de trabalho, em que as empresas multinacionais dos países centrais passam a se concentrar em produtos e serviços de alto valor agregado, no desenvolvimento tecnológico e estratégico (SARTI e HIRATUKA, 2010).

Página 103 Caderno de Ciências Sociais Aplicadas, Vitória da Conquista/BA, vol. 15, n 26, ano 15, p. 90-110, jul/dez 2018. 
As transformações tecnológicas, financeiras e institucionais, que alteraram o paradigma anterior, condicionaram uma especialização produtiva internacional. Cada região passou a se especializar de modo a aproveitar as economias de escala e escopo (SARTI e HIRATUKA, 2010). Essa forma de organização produtiva representa a assimetria produtiva, pois concentra as etapas de maior valor agregado em grandes grupos produtivos e financeiros dos países desenvolvidos, enquanto as etapas mais simples são destinadas as firmas dos países periféricos.

A seletividade no processo está associada ao fato de que a localização das diferentes etapas nos diferentes países ou regiões acontece buscando explorar os elementos fundamentais em cada etapa. Enquanto as etapas nucleares tendem a se localizar nos países centrais, as demais etapas passaram a ser realizadas crescentemente nos PED. A hierarquização que se observa ao nível das firmas acaba se reproduzindo ao nível dos países (SARTI e HIRATUKA, 2010, p. 9).

Nesse sentido, é importante a participação do Estado, de modo a direcionar os investimentos para determinados setores e reduzir as assimetrias produtivas e financeiras. Não obstante, Sarti \& Hiratuka (2010) observam que a forma de inserção dos países periféricos no processo de mundialização não foi homogênea, mas dependeu da atuação do Estado na promoção de uma política de defesa, fortalecimento e expatriação de suas firmas.

Os países da América Latina, os mais fragilizados na crise da dívida na década de 1980, passaram a adotar políticas liberais de desregulamentação e privatizações na década seguinte (COUTINHO e BELLUZZO, 1996). Na divisão internacional do trabalho, essas economias se especializaram em atividades de baixo valor agregado, enquanto os países periféricos da Ásia se dedicaram a setores intensivos em tecnologia (SARTI e HIRATUKA, 2010).

No caso brasileiro, a inserção externa das empresas nacionais teve início na década de 1980, nos setores financeiros, de construção civil, extração mineral e na produção de algumas commodities (HIRATUKA e SARTI, 2011). Já o mercado interno passou a ser mais dependente do capital financeiro-produtivo internacional, cujo interesse seria apenas consolidar posição no mercado nacional (SARTI e HIRATUKA, 2010), reduzir custos e especular.

Nos anos 2000, o Brasil passou a adotar uma política de "Campeões Nacionais", na qual o Estado assumiu papel de protagonista no fortalecimento de setores considerados estratégicos. Os setores de saúde, comunicação, da construção civil e commodities foram os mais beneficiados (PINHEIRO, 2010).

Página 104 Caderno de Ciências Sociais Aplicadas, Vitória da Conquista/BA, vol. 15, n 26, ano 15, p. 90-110, jul/dez 2018. 
Para Almeida (2011), o marco inicial da política de campeões nacionais foi a criação da Política Industrial, Tecnológica e de Comércio Exterior (PITCE), que teve por objetivo o aumento da competitividade das empresas brasileiras por meio de um crescimento da eficiência e do desenvolvimento tecnológico.

As políticas que envolvem a criação de campeões nacionais são alvo de diversas críticas. As principais delas se referem ao tipo de investimento, voltado a setores de baixa tecnologia, e a forma em que foram financiados, mediante empréstimos subsidiados pelo BNDES (SOUZA, 2010).

Por fim, a assimetria produtiva condiciona a assimetria tecnológica, pois o desenvolvimento tecnológico se origina nas firmas especializadas em atividades de maior valor agregado. Ao mesmo tempo, a assimetria tecnológica reforça a posição hierárquica das firmas dos países desenvolvidos.

\subsection{Assimetria tecnológica}

Porter (1986) destaca que a inovação teria se tornado mais acessível às firmas menores e aos países em desenvolvimento com o auxílio de acordos de concessão de patentes e licenças, o que promoveu uma redução dos custos de produção no âmbito internacional. Sendo assim, pode-se dizer que o paradigma da mundialização caracteriza-se também por um processo de internacionalização tecnológica.

Esse processo ocorre de forma assimétrica com o aumento da concentração dos investimentos em P\&D no centro, que concede a utilização de algumas patentes às empresas dos países periféricos. A concessão tecnológica por meio de acordos interempresas torna-se a principal forma de avanço tecnológico nesses países (CHESNAIS, 1995).

Ao lado dos meios anteriores de transferência internacional de tecnologia, tais como a concessão de franquias e o comércio de patentes, apareceram novas modalidades para acordos interempresas quanto à tecnologia que, frequentemente, se tornaram o principal meio para as empresas e o país terem acesso a novos conhecimentos e às tecnologias-chave (CHESNAIS, 1995, p. 5).

Assim, pode-se afirmar que o avanço tecnológico dos países periféricos está condicionado a um paradigma de "Path Depedence", diferentemente do Schumpeteriano abordado por David (1985). O "Path Dependence" tecnológico dos países periféricos, no contexto da mundialização, é cadente ao processo de concorrência oligopolístico interno, dominado pelo interesse produtivo e financeiro das boldings globais.

Página 105 Caderno de Ciências Sociais Aplicadas, Vitória da Conquista/BA, vol. 15, n 26, ano 15, p. 90-110, jul/dez 2018. 
[...] o processo de acumulação de capital é cumulativo e path-dependent. Mesmo quando a produção ocorre internamente (favorecendo a geração de empregos, ainda que de maneira decrescente), os incrementos de produtividade se dão mediante a incorporação de tecnologia gerada externamente. Uma vez que os setores intensivos em tecnologia também estão sujeitos a processos cumulativos, a relação de dependência se torna mais complexa ao invés de ser superada (VILAÇA JÚNIOR, 2013).

O interesse do capital financeiro internacional condiciona uma taxa de retorno mínima para o setor produtivo, um dos fatores determinantes para a redução dos investimentos em inovação por parte das firmas. Outro fator é a transferência de tecnologia dos países centrais. Assim, as firmas dos países periféricos são desestimuladas a investir em inovação e tecnologia tanto pelo alto custo de financiamento quanto por acordos internacionais interempresas.

A política de direito de propriedade intelectual nada mais é do que a regulação dessa dependência (CHANG, 2004). Desse modo, o apoio dos Estados das economias periféricas é essencial para a superação do Path Dependence e na consecução do desenvolvimento econômico.

$\mathrm{Na}$ última década, o Estado brasileiro vem tomando medidas importantes, porém insuficientes. Além de aumentar sua participação no financiamento para fortalecer e internacionalizar as empresas nacionais (HIRATUKA e SARTI, 2011) com a criação do PITCE, o Estado instituiu, também em 2004, a "Lei da Inovação" que colocou as instituições públicas como os principais propulsores do desenvolvimento tecnológico nacional. Segundo dados do Instituto Nacional da Propriedade Industrial (INPI), disponibilizados à revista Época, essa medida resultou no aumento do número de patentes em quase 7 pontos percentuais, se comparados o período que vai de 2004 a 2008 com o de 2000 a 2004. Esse aumento deriva do papel atuante das universidades e outros centros de tecnologia públicos do país $^{10}$ (CORNACHIONE, 2011).

\footnotetext{
10 Segundo matéria publicada na revista Época, os cinco centros de tecnologia que mais contribuíram para a evolução no número de patentes entre 2000 e 2008 foram, respectivamente, a Petrobrás, a UNICAMP, a USP, a UFMG e a FAPESP. As pequenas e médias empresas também colaboraram de forma expressiva. E, como esperado, as grandes empresas representam uma proporção relativamente pequena no número de pedidos de patentes no Brasil, com exceção de algumas do setor de agricultura (CORNACHIONE, 2011).
}

Página 106 Caderno de Ciências Sociais Aplicadas, Vitória da Conquista/BA, vol. 15, n 26, ano 15, p. 90-110, jul/dez 2018. 


\section{Considerações finais}

O texto procurou sintetizar as principais formas de assimetria que compõem o que a literatura denomina macroestrutura financeira, a qual se estabeleceu por meio da concorrência global do capital, independentemente de este se colocar na sua forma financeira ou produtiva. Outro aspecto importante é o papel preponderante do Estado em estabelecer apoio a grandes corporações, campeões nacionais, com atuação global.

Nesse paradigma, o capital é concentrado e alocado globalmente por grandes corporações de modo a maximizar os rendimentos, sem necessariamente incorrer em qualquer tipo de atividade produtiva. Grandes indústrias se confundem com instituições financeiras e movimentam enormes somas de dinheiro, o que aumenta a instabilidade do sistema, instável por natureza.

Apesar de a maior parte do fluxo de capital ocorrer entre países desenvolvidos, o seu impacto tem efeito maior em países em desenvolvimento. Visando garantir a estabilidade cambial e manter o fluxo de capitais, os Estados dos países em desenvolvimento adotam políticas pró-cíclicas. Tais políticas afetam não apenas as contas públicas, mas são capazes de gerar períodos de inflação e valorização cambial. Esses períodos são seguidos por uma recessão, com desvalorização cambial e recrudescimento inflacionário. Em decorrência disso, períodos de recessão são marcados por elevação na taxa de juros, visando controlar os preços e, especialmente, evitar uma desvalorização desenfreada do câmbio.

O investimento nos países em desenvolvimento é afetado tanto na fase de expansão, quanto na recessão. $\mathrm{Na}$ recessão, os investimentos são desestimulados pelo aumento da taxa de juros, queda na demanda e aumento no preço do capital fixo (devido à desvalorização do câmbio e elevação da inflação). $\mathrm{Na}$ expansão, os investimentos são desviados de setores produtivos e direcionados a atividades financeiras, que apresentam rentabilidade de curto prazo condizente com as exigências do mercado.

As grandes holdings globais também atuam de modo a determinar uma divisão global do trabalho, em que processos mais especializados e com valor agregado maior permanecem em países desenvolvidos. A produção, principalmente a de componentes manufaturados com baixa e média tecnologia, é alocada para países emergentes.

Sendo assim, a macroestrutura financeira condiciona um rendimento mínimo para o capital que, determinado internacionalmente, varia de acordo com as expectativas formadas nas economias centrais. A alocação do capital para setores produtivos deve ter como pré-requisito uma rentabilidade superior às

Página 107 Caderno de Ciências Sociais Aplicadas, Vitória da Conquista/BA, vol. 15, n 26, ano 15, p. 90-110, jul/dez 2018. 
demais opções de alocação existentes no mercado, incluído as financeiras. $O$ investimento em tecnologia por parte de empresas de países periféricos se torna cada vez mais inconcebível, ao passo que esta passa a ser transferida por acordos multilaterais que, muitas vezes, possuem benefícios apenas unilaterais.

\section{Referências}

AGLIETTA, M. La Crise. Pourquoi en est-on arrivé là? Comment en sortir? Paris: Michalon, 2008.

ALMEIDA, M. POLÍTICA INDUSTRIAL E CRESCIMENTO. Radar IPEA, Rio de Janeiro, Novembro 2011.

ANDRADE, R. P. D.; PRATES, D. M. Dinâmica da taxa de câmbio em uma economia monetária periférica:uma abordagem keynesiana. Nova Economia, Belo Horizonte, maio-agosto 2012. 235-257.

BOLTON, P.; CHEN, H.; WANG., N. A Unified Theory of Tobin's q, Corporate Investment, Financing, and Risk Management. Journal of Finance, New York, 2016. Disponível em: https://www0.gsb.columbia.edu/mygsb/faculty/research/pubfiles/4438/bcw_jf_forthcoming.pdf Acesso em 09 de maio de 2016.

BRAGA, J. C. D. S. Temporalidade da riqueza: uma contribuição a teoria da dinamica capitalista. Campinas: Tese de Doutorado, 1985.

BRAGA, J. C. D. S. A Financeirização da Riqueza: A Macroestrutura Financeira e a Nova Dinâmica dos Capitalismos Centrais. ECONOMIA E SOCIEDADE, Campinas, v. 2, p. 25-57, 1993. ISSN 0104-0618.

BRUNO, M. Wage-led growth e financeirização conciliados por impulsão estatal? Uma avaliação da hipótese do caráter híbrido do regime de crescimento brasileiro. XVII Encontro Nacional de Economia Política, Rio de Janeiro, 2012.

CARNEIRO, R. Globalização financeira e inserção periférica. Economia e Sociedade, Campinas, n. 13, p. 57-92, dez. 1999.

CHANG, H.-J. Chutando a escada. São Paulo: UNESP, 2004.

CHESNAIS, F. A globalização e o curso do capitalismo de fim-de-século. Economia e Sociedade, Campinas, n. 5, p. 1-30, dez. 1995.

CINTRA, M. A.; CAGNIN, R. EUFORIA E PESSIMISMO: Os ciclos de ativos, crédito e investimento da economia americana após 1982. NOVOS ESTUDOS, n. 79, Novembro 2007. 23-44.

Página 108 Caderno de Ciências Sociais Aplicadas, Vitória da Conquista/BA, vol. 15, n 26, ano 15, p. 90-110, jul/dez 2018. 
CONTI, B. D.; BIANCARELLI, A.; ROSSI, P. Currency hierarchy, liquidity preference and exchange rates: a Keynesian/minskyan approach. Congrès de l'Association Française d'Économie Politique. Bordeaux: Université Montesquieu Bordeaux IV. 2013.

CORNACHIONE, D. Os maiores inventores do Brasil. Época, 2011. Disponivel em: <http://revistaepoca.globo.com/Revista/Epoca/0,EMI253392-15223,00-

OS+MAIORES+INVENTORES+DO+BRASIL.html>. Acesso em: 27 ago. 2014.

COUTINHO, L. G.; BELluZZO, L. G. D. M. Desenvolvimento e estabilização sob finanças globalizadas. Economia e Sociedade, Campinas, n. 7, p. 129-154, dez. 1996.

COUTINHO, L.; BELLUZZO, L. G. "Financeirização" da riqueza, inflação de ativos e decisões de gasto em economias abertas. Economia e Sociedade, Campinas, n. 11, p. 137-150, dez. 1998.

DAVID, P. A. Clio and the Economics of QWERTY. The American Economic Review, v. 75, n. 2, p. 332-337, maio 1985.

FRANKEL, J. Carried Away: Everything You Always Wanted to Know about the Carry Trade, and Perhaps Much More. Milken Institute Review, v. 10, n. 1, p. 38-45, Janeiro 2008.

GAGNON, J. E.; CHABOUD, A. P. What Can the Data Tell Us about Carry Trades in Japanese Yen? International Finance Discussion Papers. No 899: Board of Governors of the Federal Reserve System. 2007.

HIRATUKA, C.; SARTI, F. INVESTIMENTO DIRETO E INTERNACIONALIZAÇÃO DE EMPRESAS BRASILEIRAS NO PERÍODO RECENTE. IPEA, Brasília, 2011. 7-56.

IPEADATA. Disponivel em: <http://www.ipeadata.gov.br/>. Acesso em: 26 nov. 2013.

KEYNES, J. M. A teoria geral do emprego, do juro e da moeda. São Paulo: Nova cultural, 1996.

MINSKY, H. John Maynard Keynes. New York: MC Graw Hill, 2008.

OCAMPO, J. A. International asymmetries and the design of the international financial system, Santiago, n. 15, abr. 2001.

PÉREZ, C. Dinamismo tecnológico e inclusión social en América Latina: una estrategia de desarrollo productivo basada en los recursos naturales. CEPAL, Santiago, Abril 2010.

PINHEIRO, M. C. A recente política industrial brasileira. LATN, Rio de Janeiro, Setembro 2010.

PORTER, M. E. Competition and global industries: a conceptual framework. In: PORTER, M. Competition in global industries. Boston: Harvard Business School Press, 1986. Cap. 1, p. 15-60.

ROSSI, P. Política Cambial no Brasil: um Esquema Analítico. 10 Fórum de Economia FGV-EESP , São Paulo, 2013.

Página 109 Caderno de Ciências Sociais Aplicadas, Vitória da Conquista/BA, vol. 15, n 26, ano 15, p. 90-110, jul/dez 2018. 
SARTI, F.; HIRATUKA, C. Indústria mundial:mudanças e tendências recentes. Texto para Discussão: IE/UNICAMP, Campinas, dez. 2010.

SCHUMPETER, J. Capitalismo, Socialismo e Democracia. Rio de Janeiro: Fundo de Cultura, 1961.

SOUZA, A. M. BNDES, campeões nacionais, expansionismo e integração regional. III Congreso Latinoamericano de Historia Económica y XXIII Jornadas de Historia Económica. Bariloche: [s.n.]. 2010. p. 1-20.

TOBIN, J. A General Equilibrium Approach To Monetary Theory. Journal of Money, Credit and Banking, Ohio, Fevereiro 1969.

ÜLGEN, F. Schumpeterian economic development and financial innovations: a conflicting evolution. Journal of Institutional Economics, v. 10, n. 2, p. 257-277, jun. 2014.

VILAÇA JÚNIOR, A. P. REPENSANDO A DEPENDÊNCIA: Dinâmica de desenvolvimento híbrido em países subdesenvolvidos. $4^{\circ}$ Encontro Nacional da Associação Brasileira de Relações Internacionais. Belo Horizonte: [s.n.]. 2013. 